\title{
Battery Storage Demonstration Projects: an Overview across Europe
}

Divshali, Poria Hasanpor; Mäki , Kari; Evens, Corentin ; Papadimitriou, Christina; Efthymiou, Venizelos; Nieße, Astrid; Holly, Stefanie; Marinelli, Mattia; Gabderakhmanova, Tatiana; Meléndez, Joaquim Total number of authors: 15

Published in:

Proceedings of 2021 IEEE PES Innovative Smart Grid Technologies Conference Europe

Link to article, DOI:

10.1109/ISGTEurope52324.2021.9640073

Publication date:

2021

Document Version

Peer reviewed version

Link back to DTU Orbit

Citation (APA):

Divshali, P. H., Mäki , K., Evens, C., Papadimitriou, C., Efthymiou, V., Nieße, A., Holly, S., Marinelli, M., Gabderakhmanova, T., Meléndez, J., Herraiz, S., Rodríguez-Sánchez, R., Morch, A. Z., de Urtasun, L.' G., \& Fernández, G. (2021). Battery Storage Demonstration Projects: an Overview across Europe. In Proceedings of 2021 IEEE PES Innovative Smart Grid Technologies Conference Europe IEEE.

https://doi.org/10.1109/ISGTEurope52324.2021.9640073

\section{General rights}

Copyright and moral rights for the publications made accessible in the public portal are retained by the authors and/or other copyright owners and it is a condition of accessing publications that users recognise and abide by the legal requirements associated with these rights.

- Users may download and print one copy of any publication from the public portal for the purpose of private study or research.

- You may not further distribute the material or use it for any profit-making activity or commercial gain

- You may freely distribute the URL identifying the publication in the public portal 


\title{
Battery Storage Demonstration Projects An Overview Across Europe
}

\author{
Poria Hasanpor Divshali, Kari Mäki, \\ Corentin Evens \\ VTT Technical research centre \\ Espoo, Finland \\ poria.divshali@gmail.com
}

\author{
Mattia Marinelli, Tatiana \\ Gabderakhmanova \\ Technical University of Denmark \\ Roskilde, Denmark
}

Andrei Morch

SINTEF Energi AS

Trondheim, Norway

\author{
Christina Papadimitriou, Venizelos \\ Efthymiou \\ FOSS Research Centre for Sustainable \\ Energy of University of Cyprus, Cyprus
}

\author{
Joaquim Meléndez, Sergio Herraiz \\ University of Girona \\ Spain
}

\author{
Astrid Nieße, Stefanie Holly \\ OFFIS - Institute for Information \\ Technology \\ Oldenburg, Germany
}

Raúl Rodríguez-Sánchez

TECNALIA, Basque Research and

Technology Alliance

Derio, Spain

\begin{abstract}
This paper summarises results and experiences from several demonstration projects across European countries in the field of battery energy storage system (BESS) integration to the power system. These research projects are selected among research institutes and universities that are part of the European Energy Research Alliance (EERA) Joint Program on Smart Grids. The paper categorizes these projects according to the demonstrated applications of BESS and then reviews specific aspects of each project. This paper provides an opportunity to find out the summary of the most recent results as well as challenges and open research questions in projects focusing on different BESS application in the power system.
\end{abstract}

Keywords-Ancillary services, Demonstration projects, Battery storage system, Grid integration, Renewable Energy Sources.

\section{INTRODUCTION}

Following the European Union ambitious to reduce 55\% of greenhouse gas emissions by 2030, the future energy system needs to host a high penetration level of renewable energy sources (RES), at least 32\% at the EU level [1]. In these circumstances, the power system will face new technical challenges and requires to host energy storage systems to mitigate these challenges [2].

There are different energy storage technologies, which can be integrated into the power system. Among them, battery energy storage systems (BESS) become one of the popular solutions, due to fast response times and a steady reduction in required investment cost [3]. However, more research is required regarding integration methods while providing various services for the power system.

BESS integrated into the power system have different specifications and integration methodologies. This paper will present a summary of 11 demonstration projects, across European countries in the field of BESS integration. These projects are performed (partly) by members of the European Energy Research Alliance (EERA) Joint Program on Smart Grids, Sub-program 2, Storage integration.

EERA brings together universities and public research centres in almost all European countries to align and synchronize their research and fulfil the strategic technology plan adopted by the European Union in 2008.

\author{
Laura Giménez de Urtasun, Gregorio Fernández \\ CIRCE Foundation \\ Zaragoza, Spain
}

\section{BESS INTEGRATION INTO POWER SYSTEM}

The BESS can be integrated into the power system for different purposes. The application of BESS in the power system can be divided into three main categories: 1) Selfbalancing, 2) Flexibility provision, and 3) Hosting capacity improvement. However, from an economical point of view, BESS could be used for multi-purposes at the same time to make it more viable.

Table I categorises the selected projects based on their applications demonstrated and also gives some administrative information about these projects. Fig. 1 shows the power rate and capacity size of BESS used in these research and innovation projects.

The next section will present examples of demonstration projects with BESS integrated into the power system for each of these applications.

\section{SUMMARY INFORMATION ON THE SELECTED PROJECTS}

\section{A. Self-balancing}

Most RES, such as wind turbines and photovoltaics, have uncontrollable power output. Therefore the high share of RES adds significant uncertainty to the power system. In these circumstances, keeping the real-time balance between production and consumption is one of the main technical

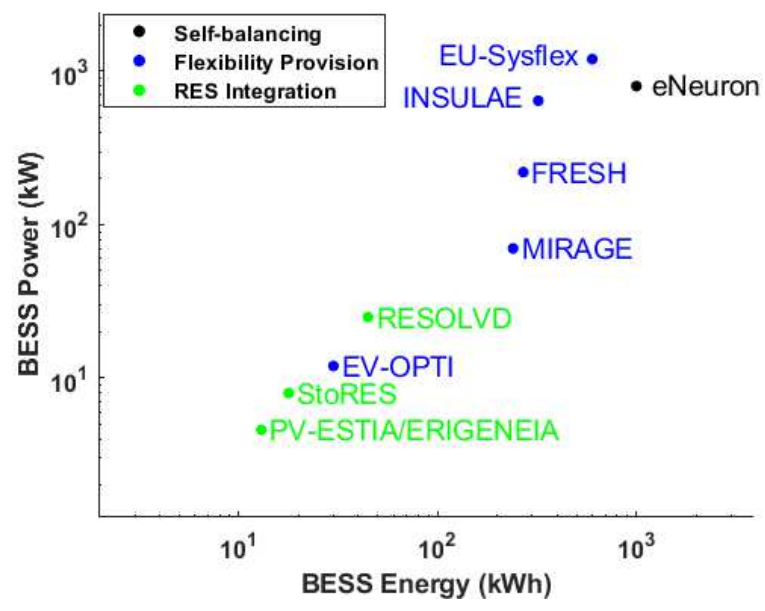

Fig.1. The power rate and capacity of the BSS 
TABLE I - Projects administrative information

\begin{tabular}{|c|c|c|c|c|c|}
\hline Category & $\begin{array}{l}\text { Project name and } \\
\text { (number of } \\
\text { partners) }\end{array}$ & Website & Duration & $\begin{array}{l}\text { Budget } \\
\text { M€ }\end{array}$ & Funding agency \\
\hline Self-balancing & eNeuron (17) & https://eneuron.eu/ & $\begin{array}{l}48 \text { months } \\
(2020-2024)\end{array}$ & 4.5 & Horizon 2020 \\
\hline \multirow{5}{*}{$\begin{array}{l}\text { Flexibility } \\
\text { provision }\end{array}$} & EU-Sysflex (34) & https://eu-sysflex.com/ & $\begin{array}{l}48 \text { months } \\
(2017-2021)\end{array}$ & 26.5 & Horizon 2020 \\
\hline & INSULAE (26) & http://insulae-h2020.eu/ & $\begin{array}{l}48 \text { months } \\
(2019-2023)\end{array}$ & 12.0 & Horizon 2020 \\
\hline & FRESH (5) & $\begin{array}{l}\text { https://hhla.de/en/company/innovation/re } \\
\text { search-and-funding/fresh }\end{array}$ & $\begin{array}{l}24 \text { months } \\
(2019-2021)\end{array}$ & 2.1 & $\begin{array}{c}\text { German Federal Ministry for } \\
\text { Economic Affairs and } \\
\text { Energy }\end{array}$ \\
\hline & MIRAGE (2) & $\begin{array}{l}\text { https://www.offis.de/en/offis/project/mir } \\
\text { age.html }\end{array}$ & $\begin{array}{l}18 \text { months } \\
(2019-2020)\end{array}$ & - & Industrial funding \\
\hline & $\begin{array}{l}\text { EV-OPTI } \\
\text { MANAGER (2) }\end{array}$ & $\begin{array}{l}\text { https://www.urbener.com/proyecto-ev- } \\
\text { opti-manager/ }\end{array}$ & $\begin{array}{l}36 \text { months } \\
(2015-2018)\end{array}$ & 1.2 & FEDER \\
\hline \multirow{5}{*}{$\begin{array}{l}\text { Hosting } \\
\text { capacity } \\
\text { improvement }\end{array}$} & RESOLVD (7) & https://resolvd.eu/ & $\begin{array}{l}36 \text { months } \\
(2017-2020)\end{array}$ & 3.8 & Horizon 2020 \\
\hline & PV-ESTIA (9) & https://www.pv-estia.eu & $\begin{array}{l}32 \text { months } \\
(2017-2020)\end{array}$ & 1.2 & $\begin{array}{l}\text { Balkan-Mediterranean 2014- } \\
2020\end{array}$ \\
\hline & ERIGENEIA (6) & $\begin{array}{l}\text { http://www.foss.ucy.ac.cy/projects/erige } \\
\text { neia/index.php }\end{array}$ & $\begin{array}{l}36 \text { Months } \\
(2018-2021)\end{array}$ & 1 & SOLAR ERANET COFUND \\
\hline & StoRES (10) & https://stores.interreg-med.eu/ & $\begin{array}{c}36 \text { months } \\
(2016-2019)\end{array}$ & 2 & $\begin{array}{l}\text { The Transnational } \\
\text { Cooperation Programme } \\
\text { Interreg Mediterranean }\end{array}$ \\
\hline & FlexPlan (13) & https://flexplan-project.eu & $\begin{array}{l}36 \text { months } \\
(2018-2022)\end{array}$ & 4.45 & Horizon 2020 \\
\hline
\end{tabular}

challenges of future power systems, especially in an area with limited interconnection capacity, such as islands. In this category, the eNeuron project focuses on the self-balancing of energy communities.

\section{1) eNeuron}

The eNeuron (Green Energy Hubs for Local Integrated Energy Communities Optimisation) project aims to develop innovative tools for the optimal design and operation of local energy communities (LECs) integrating distributed energy resources and multiple energy carriers at different scales. The project develops the Energy Hub concept, as a conceptual model for controlling and managing multi-carrier and integrated energy systems to optimize their architecture and operation. The concept will reside on a set of optimization tools and methodologies to optimally plan and operate integrated LECs through the optimal selection and use of multiple energy carriers and by considering both short- and long-run priorities. The project includes validation and refining of the methodologies in four national pilots, including the Norwegian pilot, Skagerak Energilab - fully operational football stadium with $4300 \mathrm{~m} 2 \mathrm{PV}$ panels installed with 800 $\mathrm{kW}$ capacity and supporting BESS with $1 \mathrm{MWh}$ with power electronics allowing several operational modes for the unit, including fully islanded operation.

\section{B. Flexibility provision}

Traditionally, conventional power plants provide some ancillary services, such as frequency and voltage regulation and adjust quickly their productions to counteract any change in the power system. However, providing ancillary services in modern power systems are more challenging, because of 1) the shift from traditional power plants to distributed generations, such as RES, with a variable and less-controllable power output; and 2) power system deregulation [3], [4].
To mitigate these challenges, transmission system operators (TSO) encourage all energy sectors to provide ancillary services and system support. In these circumstances, different sources can be used for flexibility provision, among them BESS attracts a great deal of attention in recent years [5]. The distinction between this application and self-balancing is that here the BESS participate in a market and sell its product, while in self-balancing, it focuses just on mitigating technical challenges. The following projects focus on the market strategy of providing different flexibility products by BESS.

\section{1) EU-Sysflex}

The EU-SysFlex (Pan-European system with an efficient coordinated use of flexibilities for the integration of a large share of RES) project tests a high level of integration of RES in the pan-European electricity system. The EU-SysFlex project aims to identify issues and solutions associated with integrating large-scale renewable energy and create a plan to provide practical assistance to power system operators across Europe. In the Finnish Demonstration, the potential of BESS to provide flexibility, particularly frequency regulation, was investigated. In this regards, the bidding strategy and online control methodology of BESS are developed to participate in the flexibility market. The detailed methodology can be found in [3].

The results show that the best product for BESS in the Finnish flexibility market is FCR-N (frequency containment reserve for normal operation). Besides, considering the current revenue of the FCR market and storage cost, it takes more than eight years to compensate for the storage initial investment.

The main challenge of BESS to provide FCR in the Finnish flexibility market is the technical requirement that makes the BESS unit have storage capacity for at least 30 minutes. Although most of the frequency deviation does not 
last for 30 minutes, this requirement leads to a very large storage bank and consequently expensive initial investment.

\section{2) INSULAE}

INSULAE (Maximizing the impact of innovative energy approaches in the EU islands) aims at fostering the deployment of technological solutions for the EU islands decarbonization. It will be achieved by the development and demonstration on three islands - Bornholm (Denmark), Madeira (Portugal), and Unije (Croatia) - of a set of interventions linked to seven replicable use cases and subsequent creation of tools for the replicability enhancement and the decision making support, such as island Action Plans and an Investment Planning Tool [6].

One of the project use cases, that takes place on the Danish island of Bornholm, is dedicated to the demonstration of a DC microgrid, comprised of a $624 \mathrm{~kW} / 312 \mathrm{kWh}$ innovative reconfigurable battery, two $175 \mathrm{~kW} \mathrm{EV} \mathrm{fast} \mathrm{chargers,} \mathrm{and} \mathrm{a}$ $61 \mathrm{~kW}$ PV facility. The battery technology is based on a novel approach, which provides a possibility to repeatedly engage/disengage individual battery cells in a real-time fashion, and by this form a topology that can meet the request of the specific appliance it is connected to [7], [8].

The project enters its demonstration stage in June 2021. The storage system, part of the DC microgrid, will be experimentally tested towards performing: - maximum power point tracking of $\mathrm{PV}$, - power reference tracking at the grid connection point, - fast EV charging, - grid services (such as frequency control) provision [9].

The main outcome of the use case demonstration will be the verified hardware and software BESS solution, ready for the commercialisation and replication, capable of: - fulfilling high power requests from EV fast chargers while being connected to the grid with a limited capacity, - reducing the impact of high-power EV chargers on the distribution grid, contributing to the frequency regulation, - effective integration of RES (specifically, increase of PV selfconsumption).

Challenges that have been faced during the preparation of the demonstration were: - delays in the hardware/software development due to the novelty of the technology, - defining a demonstration site that fits the use case scope and getting an agreement of hosting stakeholders.

\section{3) FRESH}

The FRESH project aims to integrate the automated guided container transport vehicles (AGVs) into the NEXT Kraftwerke Virtual Power Plant (VPP) to participate in the primary capacity reserve market. By 2022, the approximately $100 \mathrm{AGVs}$ in use at Terminal Altenwerder for the transport of containers will be completely converted to fast-charging lithium-ion batteries, which is supported financially by the European Regional Development Fund (ERDF). In purely mathematical terms, they could then provide 4 megawatts for the energy market at the 18 electric charging stations.

The main achievement of the FRESH project will be hardware and software developed to integrate electric fleets to system stabilizing VPP. The detailed results can be found in [10].
The main challenge to implement this idea is integrating storage capacity as a flexibility provision source while ensuring logistics' requirements at the container terminal.

\section{4) MIRAGE}

In order to make use of today's still comparatively expensive storage systems in an economically and technically optimal way, the industrially funded project MIRAGE (MultiPurpose Battery Storage Swarm) investigated the requirements and challenges regarding multi-purpose usage of interconnected, small BESS. The main challenge to implement multi-purpose usage is integrating storage capacity as a flexibility provision source while ensuring primary use case obligations of industrial / business customers. For example, BESS can provide peak-shaving capabilities in an industrial setting, while in off-peak times simultaneously providing flexibility for power market applications. For this purpose, storage systems have been equipped with intelligent, autonomous software agents that control individual BESS and form a self-organising storage swarm in order to use aggregated degrees of freedom on flexibility markets. Machine learning and distributed artificial intelligence are used to analyse, forecast and optimise flexibility potentials in a distributed way.

The main achievement of the MIRAGE project is the hardware and software developed to integrate aggregated stationary BESS into the energy market and balancing purposes, as a multi-purpose application. The developed system has been tested in a field trial. Due to industrial funding, detailed results are currently not publicly available. However, the software framework MANGO for creating intelligent battery agents has been published as open-source software [11] under the MIT license.

\section{5) EV-OPTI MANAGER}

The EV-OPTI MANAGER (EV Charging Manager optimization demand) project focus on developing and demonstrating a portfolio of products and services to improve the demand forecast, consumption management, energy purchase management and storage; and provision of electricity. This project considers two types of electric system agents: direct consumer and EV charging services provider. The aim is to reduce the energy costs, to reduce the peaks in the demands, and to ensure the energy supply of recharging infrastructures for the electric vehicle. The solutions developed in EV-OPTI MANAGER include energy storage based on the regeneration of batteries (second-life batteries), as a way for reducing the costs of BESS and the associated environmental impact.

The main outcome of this project is the control and management system (hardware and software) that enables efficient management of the electric energy for the clients. This management system can be the basis for the provision of ancillary services to the grid. Along with the project evolution, it was demonstrated that one of the most important uses of distributed storage systems is the provision of ancillary services to grid operators. The detailed outcome can be found in the project webpage and [12].

The main challenge in this project is to adapt the operation of the system, including batteries storage system, to an electric system, which is constantly changing and evolving. 


\section{Hosting capacity improvement.}

Due to the distributed nature of wind and solar, a majority of RES connected to electrical distribution grids. Although distributed generators have several advantages, e.g. loss reduction, they may create some technical challenges, such as reverse power flow and voltage rise. These technical challenges limit the maximum amount of power that can be injected by RES in distribution grids, called the hosting capacity $(\mathrm{HC})[5]$.

Among all different solutions for increasing the $\mathrm{HC}$ in distribution grids, the following projects focus on using BESS to improve the HC. Due to the cost of the BESS, BESS used for this application usually has a smaller capacity as shown in Fig. 1.

\section{1) RESOLVD}

RESOLVD (Renewable penetration levered by efficient Low Voltage Distribution) aims to improve the efficiency and the $\mathrm{HC}$ of distribution networks in a context of highly distributed renewable generation by introducing flexibility, through storage management, and control in the low voltage (LV) grid. This project builds up an enhanced LV grid monitoring with (local) wide area monitoring capabilities to detect and forecast critical episodes (congestion, faults, voltage variations and quality of supply) and to schedule optimal grid configuration and energy management through heterogeneous storage elements. The interoperation of these technologies, together with legacy systems (SCADAM AMI and MDMS) in a secure and safe framework will allow a more efficient grid operation and a maximised HC. The demonstrative pilot consists of two secondary substations with PV prosumers and equipped with an interconnection between the main feeders.

The achievement of this project is an innovative advanced power electronics device, with integrated storage management capabilities, providing both switching and energy balancing capacities for optimal grid operation. The developed method control continuously power flow between storage and the grid based on the demand and generation forecasting at the customer level results to flattened demand curve at the substation level. The detailed methodology of the project can be found in [13]

The main challenges of the project are: 1) Maximise the use of actual infrastructures through active energy management and balancing at LV level; 2) Reduce DSO planning uncertainty by means of demand and generation forecasting and application of robust optimisation methods for grid planning; 3) Improve quality of supply (EN 50160) through local energy management provided by power electronics and batteries (phase balancing, harmonic compensation, voltage control), facilitating flexibility management and maximal renewable generation; 4) Reduce losses through local use of energy ("zero km" paradigm); 5) Increase renewable energy sources hosting capacity in LV, facilitating evacuation of non-locally consumed generation; 6) Reduce energy not supplied from distributed energy resources due to improved network management; 7) Reduce demand peak at secondary substation; 8) Deliver a secure-by-design smart grid architecture through threat modelling, stringent implementation and penetration testing

\section{2) PV-ESTIA}

PV-ESTIA (Enhancing storage integration in buildings with Photovoltaics) aims to enhance the integration of PV and Energy Storage Systems in the building environment in 5 pilot areas, thus facilitating the transition towards Nearly Zero Energy Buildings. This project focus on identifying and tackling barriers in PV deployment and providing a new energy management solution for residential and commercial buildings, taking into consideration potential interactions with the electrical grid. The methodology is based on transforming buildings into a controllable energy source and designing and implementing proper policies and regulations.

The detailed methodology of the project can be found in [14], [15], while the main achievements are listed as follows:

- An innovative management scheme of hybrid $\mathrm{PV}+$ storage systems, making buildings gridfriendlier

- A generalized model assessing alternative policies related to the implementation of such hybrids;

- An online tool providing profitability estimation of such systems

- An advanced tool evaluating multiple policy scenarios

- Set of joint regulation recommendations in the form of a roadmap and joint policy recommendations targeting grid operators and relevant stakeholders

The main challenges as confronted within the PV-ESTIA project can be summarized as follows: 1) Heating and cooling demand can vary seasonally by different trends. This may vary the profitability of the system and affect the control strategy; 2) Load matching indicators of a building are linked to the ratio between the households' annual electricity generation and demand. This affects the $\mathrm{CO}_{2}$ emissions reduction per installed $\mathrm{kWp}$ and perplex the regulation or policy recommendations.

\section{3) ERIGENEIA}

The Erigeneia (Enabling rising penetration and added value of photovoltaic generation by implementation of advanced storage systems) project focuses on increasing the value of PV by solving issues associated with system integration. For this purpose, Erigeneia targets to deliver an integrated energy management system (EMS) that combines the PV generation and BESS both for community and residential energy storage. Erigeneia goes a step beyond the current EMS, proposing innovative solutions for increasing the PV penetration, while providing grid-supportive strategies, such as power smoothing, frequency support and voltage regulation for both interconnected and islanded grids.

The target of Erigeneia is to deliver products and services that will be ready-to-market that are currently not available. The main feature is based on the development of a central and local EMS that will cooperate with optimally sized storage systems and intra-hour forecasting methods, to maximize the benefit of the PV installations in the distribution grids. More specifically, the power fluctuations will be absorbed, alleviating the negative impact of the PV nature. The advanced forecasting tool will help the DSO to manage the resources more effectively. The detailed methodology and results can be found in [16]. 
Future research stemming from this project are: 1) Enhancement of the forecasting tool i.e. include load forecasting or/and market forecasting. 2) Develop solutions to join and be validated under the context of the market and the future markets. 3) Enhance the EMS to employ also other energy carrier systems such as thermal, transport etc.

\section{4) StoRES}

The objective of the StoRES (Promotion of higher penetration of Distributed PV through storage for all) is to boost PV self-consumption in the Mediterranean (MED) through an optimal storage solution via testing smart solutions in 6 MED islands and rural areas. StoRES aims to increase the PV penetration in the energy mix of these areas in the MED by integrating PV and Energy Storage Systems under an optimal market policy and by removing the constraints of grid reliability and RES intermittency.

The main achievements of the project are as follows:

- Implemented and tested hybrid PV+Storage systems as pilots in the participating countries

- Developed tools (StoRES Living Lab, StoRES Online PV+Storage Optimisation Tool)

- Conduct a Cost-Benefit Analysis for residential PV+Storage systems

- Conduct a PV+Storage Monitor assessing the feasibility of residential PV+Storage systems in the participating countries and their proximity to Grid Parity

- Data Analysis \& Future Scenarios exploration

- Policy recommendations

- Training courses \& organised workshops

- Engagement of stakeholders (31 municipalities, etc.)

The main challenge of the project is to achieve high PV penetration in the energy mix of the regions involved through solving all market/technical/grid/tariff issues, without compromising grid stability and security of supply.

\section{5) FlexPlan}

The FlexPlan (Advanced methodology and tools taking advantage of storage and FLEXibility in transmission and distribution grid PLANning) project aims at establishing a new grid planning methodology considering the opportunity to introduce new storage and flexibility resources in electricity transmission and distribution grids as an alternative to building new grid elements. In the sight of this, FlexPlan creates a new innovative grid planning tool whose ambition is to go beyond the state of the art of planning methodologies, by including the following innovative features: integrated T\&D planning, full inclusion of environmental analysis, probabilistic contingency methodologies replacing the N-1 criterion as well as optimal planning decision over several decades. However, FlexPlan is not limited to building a new tool but also uses it to analyse six regional cases covering nearly the whole European continent, aimed at demonstrating the application of the tool on real scenarios as well as at casting a view on grid planning in Europe till 2050. The project ends up formulating guidelines for regulators and the planning offices of TSOs and DSOs.
One of the tasks of the project is to develop a preprocessing tool to select a shortlist of network extension candidates. This software is in charge of providing a reduced number of storage and demand response candidates to the planning tool, in the most suitable grid buses. Then, the later selects the optimum technologies and sizes among the candidates, considering also new lines and phase-shifting transformers as eligible.

The final result should be the development of a network planning methodology and tool that considers storage and DR as a candidate for network extension. The detailed methodology and results can be found in the project webpage (See table I).

To achieve this goal, several challenges exist, such as the characterization of local constraints associated with network nodes, the optimization considering several flexibility options and three different time horizons, and the consideration of environmental issues in the planning procedure.

\section{CONCLUSIONS}

This paper presented eleven European demonstration projects that investigate the integration of BESS in the power grid. Although European countries have different sources of energy productions, regulations, electricity markets and prices, etc., these projects show similar interests in BESS as a possible solution to mitigate the variability of RES and at the same time provide ancillary services to the grid.

According to the BESS characteristics and their integration methodology, the BESS applications in these projects are divided into three categories. 1) Self-balancing, 2) Flexibility provision and 3) Hosting capacity improvement.

In the self-balancing application, the primary goal of BESS is keeping the system balancing and maintaining stability. In this application, the focus will be the mitigation of technical challenges, e.g. energy balancing in an island. On the other hand, in the flexibility provision application, BESS will participate in a market to provide a portfolio of flexibility products to maximise energy efficiency in the most costefficient way. In this type of projects, a forecast methodology and a bidding strategy according to the market requirements are developed. In the last application, hosting capacity improvement, usually smaller BESS are installed in distribution grids to mitigate the voltage and current deviations and postpone or confine the grid extension.

\section{ACKNOWLEDGEMENT}

The authors are grateful to the various funding agency listed in Table I for the financial support to the projects.

\section{REFERENCES}

[1] European Commission, "Clean energy for all Europeans," 2019. doi: $10.2833 / 9937$

[2] ETIP SNET, "VISION 2050 - Integrating Smart Networks for the Energy Transition: Serving Society and Protecting the Environment," 2019. https://www.etip-snet.eu/etip-snet-vision-2050/ (accessed Apr. 06, 2020).

[3] P. Hasanpor Divshali and C. Evens, "Optimum Operation of Battery Storage System in Frequency Containment Reserves Markets," IEEE Transactions on Smart Grid, vol. accepted, 2020.

[4] P. Hasanpor Divshali and B. J. Choi, "Electrical market management considering power system constraints in smart distribution grids," Energies, vol. 9, no. 6, pp. 1-30, 2016, doi: 10.3390/en9060405. 
[5] P. Hasanpor Divshali and L. Soder, "Improving Hosting Capacity of Rooftop PVs by Quadratic Control of an LV-Central BSS," IEEE Transactions on Smart Grid, vol. 10, no. 1, pp. 919-927, 2019, doi: 10.1109/TSG.2017.2754943.

[6] I. B. Sperstad et al., "Cost-benefit analysis of battery energy storage in electric power grids: Research and practices," in IEEE PES Innovative Smart Grid Technologies Conference Europe, Oct. 2020, vol. 2020October, pp. 314-318. doi: 10.1109/ISGTEurope47291.2020.9248895.

[7] J. Engelhardt, T. Gabderakhmanova, G. Rohde, and M. Marinelli, "Reconfigurable Stationary Battery with Adaptive Cell Switching for Electric Vehicle Fast-Charging," $2020 . \quad$ doi: 10.1109/UPEC49904.2020.9209774.

[8] J. Engelhardt, J. M. Zepter, T. Gabderakhmanova, G. Rohde, and M. Marinelli, "Double-String Battery System with Reconfigurable Cell Topology Operated as a Fast Charging Station for Electric Vehicles," Energies, vol. 14, no. 9, 2021, doi: 10.3390/en14092414.

[9] T. Gabderakhmanova et al., "Demonstrations of DC Microgrid and Virtual Power Plant Technologies on the Danish Island of Bornholm," Sep. 2020. doi: 10.1109/UPEC49904.2020.9209853.

[10] S. Holly et al., "Flexibility management and provision of balancing services with battery-electric automated guided vehicles in the Hamburg container terminal Altenwerder," Energy Informatics, 2020, doi: 10.1186/s42162-020-00129-1.

[11] "mango-agents / mango · GitLab." https://gitlab.com/mangoagents/mango (accessed Jan. 29, 2021).

[12] G. Fernández, J. Almajano, E. García, H. Bludszuweit, S. MacHín, and J. F. Sanz, "Control structure for optimal demand-side management with a multi-technology battery storage system," in IEEE International Conference on Emerging Technologies and Factory Automation, ETFA, Sep. 2019, vol. 2019-September, pp. 754-759. doi: 10.1109/ETFA.2019.8869314.

[13] J. M. Frigola, H. Tuiskula, and R. Gallart, "RESOLVD RENEWABLE PENETRATION LEVERED BY EFFICIENT LOW VOLTAGE DISTRIBUTION GRIDS . SPECIFCATIONS AND USE CASE ANALYSIS," 2019.

[14] V. Gjorgievski et al., "Sizing of Electrical and Thermal Storage Systems in the Nearly Zero Energy Building Environment - A Comparative Assessment," 2019. doi: 10.1109/SyNERGYMED.2019.8764142.

[15] V. Gjorgievski et al., "Simulation based approach for determining the battery control strategy of a PV and battery pilot system," Jun. 2019. doi: 10.1109/ELMA.2019.8771659.

[16] M. F. et Al, "Enabling rising penetration and added value of photovoltaic generation by implementation of advanced storage systems," 2019. 